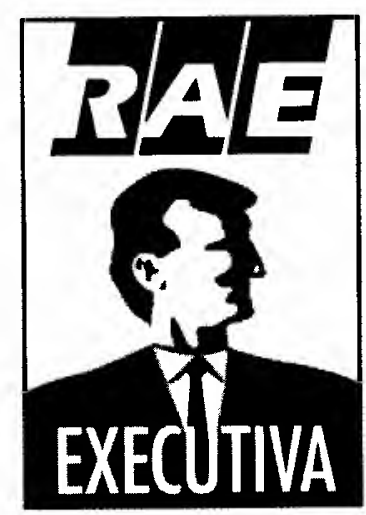

\title{
ESTRUTURA VERSUS ESTRUTURA: O CASO JAPONÊS
}

*Gilmar Masiero

A "estrutura de castelos" das empresas japonesas refletem vários aspectos culturais e administrativos da sociedade japonesa .

The "castle struture" of the Japanese companies is a reflection of various cultural and administrative aspects of the Japanese society.

" Pesquisador e Professor da Universidade Estadual de Maringá, PR.

Em Strategy and structure, The visible hand e Scale and scope $e^{1}$, Alfred Chandler faz análises $e x$-post e consolida conhecimentos, que são reconhecidos mundialmente. Segundo ele, a competição oligopolista mol-

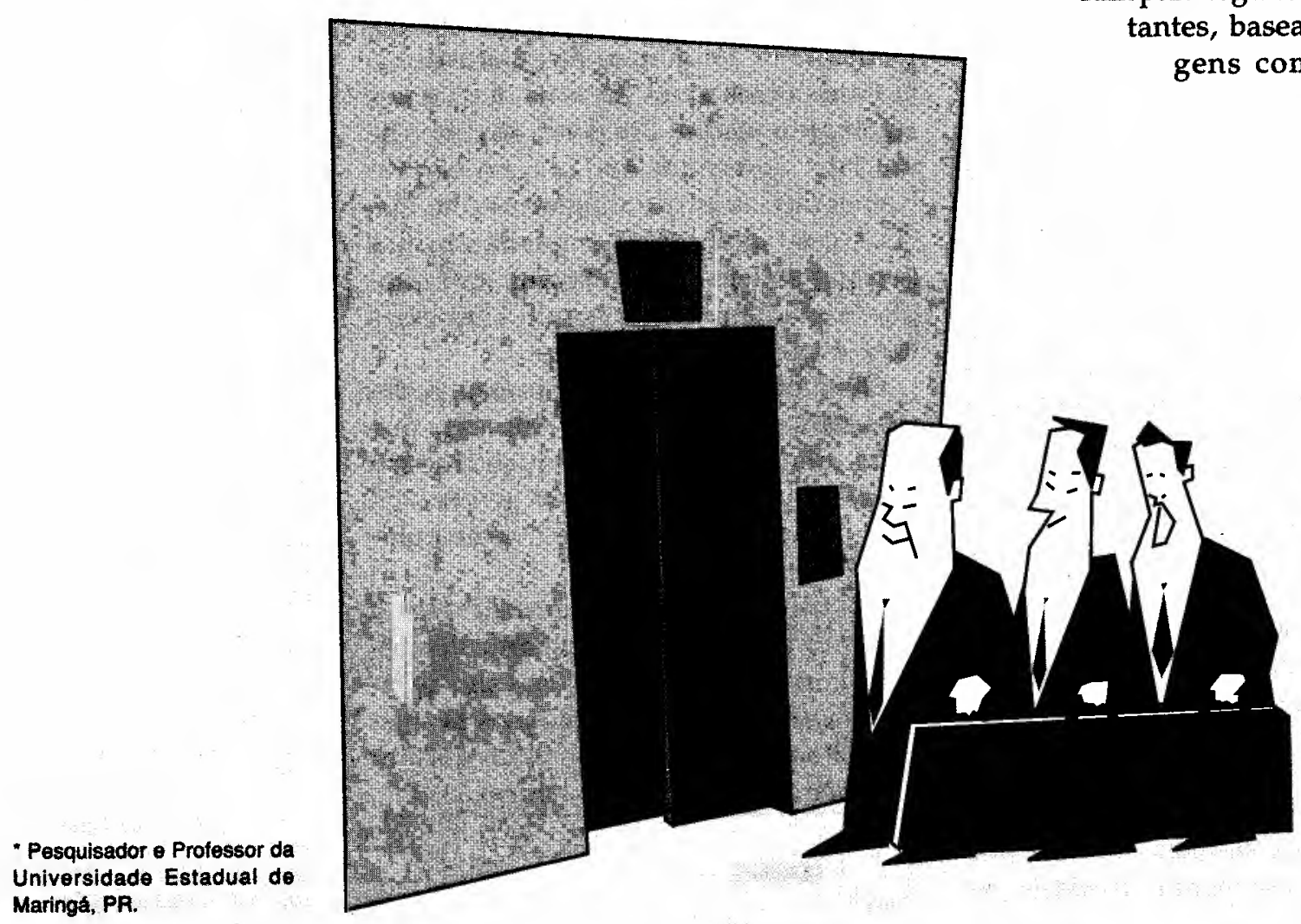

da produtos e capabilities ${ }^{2}$ específicas de trabalhadores e gerentes. Essas capabilities mais os lucros retidos tornaram-se a base para o crescimento futuro das empresas. Muitas cresceram através da expansão para novos mercados. Outras se expandiram para regiōes geográficas distes, baseadas nas vantagens competitivas das 
capabilities organizacionais, desenvolvidas através da exploração das economias de escala, e/ou para outras indústrias, baseadas na exploração das economias de escopo.

Empresas líderes, com baixos custos unitários e altos índices de produtividade, geralmente possuem sistemas administrativos eficazes, capazes não somente de capturar conhecimento acumulado e experiência, mas também de redirecioná-los para a satisfação das sempre dinâmicas necessidades e desejos dos consumidores. Além das estruturas e estratégias, é no nível dos sistemas que muito da variação do desempenho das empresas pode ser explicado. Nesse nivel, onde é necessário um elevado grau de especificidade, as complexidades das análises comparativas, entendidas aqui em seu caráter confuso (reprodutor e consolidador da autoridade) ou no sentido de complicado (desafiador e investigador do conhecimento), salientam-se, $\mathrm{e}$ generalizações, como as de Chandler, tornam-se de pouca utilidade para a realidade concreta da empresa.

Diferentes conceitos, modelos e técnicas são extensivamente utilizados em estudos comparativos, sendo inesgotável o número de generalizações por parte de seus praticantes. Muitas dessas generalizações assumem pressupostos euro-americanos como base universal de apoio a suas argumentações e, normalmente, colocam pouca ênfase nas múltiplas influências ambientais e históricas no desenvolvimento dessa ou daquela sociedade. Embora o desenvolvimento das tecnologias de transporte e telecomunicações tenha impulsionado a globalização econômica do mundo, a cultura e fatores sociais característicos de cada sociedade têm preservado identidades locais e regionais.

Se essas considerações fazem sentido, parece-nos importante relatar alguns aspectos do dinâmico desenvolvimento econômico oriental, mais especificamente o desenvolvimento japonês. Num primeiro momento, destacamos algumas características formadoras da "estrutura cultural" japonesa e, num segundo momento, descrevemos algumas características da estrutura das empresas japonesas.

\section{ESTRUTURA CULTURAL}

$\mathrm{Na}$ busca de um adequado equilíbrio entre as vontades industrializantes de determinada sociedade e de outras vontades, sempre receosas da perda de seus valores culturais elementares, diferentes governos participaram ativamente na promoção da educação, da pesquisa científica, de investimentos em infra-estrutura e da manipulação de suas diferentes políticas macroeconômicas. A intervenção governamental, direta ou indireta, sempre esteve presente em maior ou menor grau em todo o desenvolvimento industrial europeu, americano ou asiático. Na Ásia, arranjos econômicos e sociais especiais possibilitaram, no pós-guerra, grande dinamismo industrial a alguns países da região. Entre esses países, a liderança do Japão é incontestável.

A presença do Estado num amplo espectro de atividades relacionadas ao crescimento das empresas sempre foi característica marcante do desenvolvimento japonês. Governo e grandes empresas têm cooperado em todas as atividades produtivas. O Estado não negligenciou os interesses privados e tem coordenado o desenvolvimento japonês durante todo o período do pós-guerra. Sua burocracia, trabaIhando próxima a todos os agentes econômicos, estabelece as "visões" (planos) a serem seguidas por todas as empresas japonesas e não-japonesas operando no Japão. Essas últimas sempre foram de presença inexpressiva no desenvolvimento industrial japonês.

O processo de industrialização contou com a habilidade japonesa de se desenvolver economicamente através da adoção de tecnologias ocidentais, ao mesmo tempo que mantinha e reproduzia suas particularidades culturais. Nesse processo, o sistema educacional desempenhou, e ainda desempenha, papel fundamental. Ogoverno japonês já considerava a educação, no Ato Educacional de 1872, a chave para o sucesso na vida, fato que ninguém poderia ou pode contestar.

Esse ato governamental, que tinha como objetivo básico a alfabetização total do país, declarava textualmente que "...em
1. CHANDLER, Altred D. Scale and scope: the dynamics of industrial capitalism. Cambridge: Harvard University Press, 1990. 860p; _. . The vislble hand: the managerial revolution in American business. Cambridge: Harvard University Pross, 1977. 608p; Strategy and structure: chapters in the history of the American industrial enterprise. Cambridge: MIT Press, 1962. 463p.

2. A traducão de capabllities para o português 6 : capacidade, aptidăo ou habilidade, que nåo traduz a idéia de processos que possuem determinadas caracteristicas de se auto-ajustarem e se desenvolverem, mais comum no contexto empresa rial. Por esse mottvo, mantémso a palavra em ingles. 
Gráłico 1

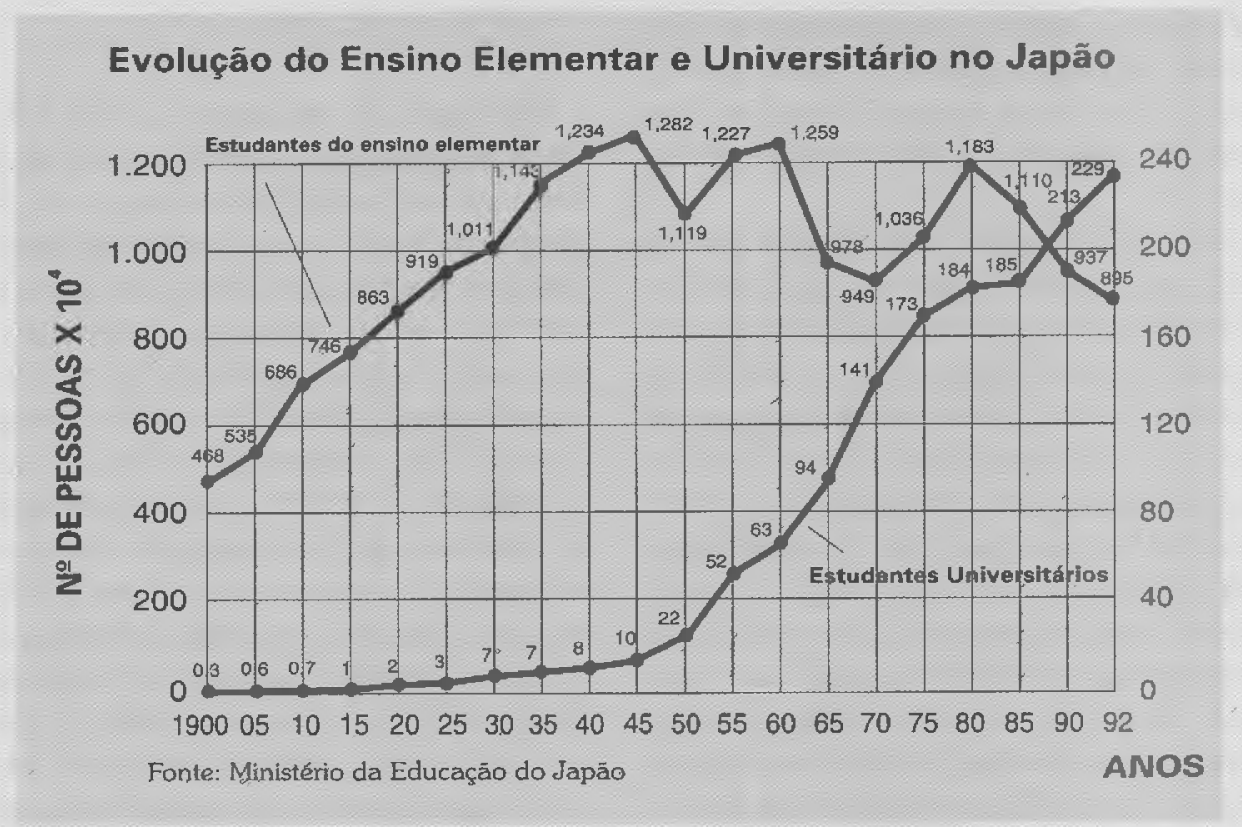

uma vila não deverá existir nenhuma casa sem educação e, em uma casa, nenhum individuo sem educação"3. Estatísticas governamentais do Ministério da Educação demonstram o acelerado crescimento do número de alunos que concluíram o ensino elementar até 1945. Após esse ano, mais especificamente após a Lei de Educação Escolar de 1947, o número de universitários graduados tem apresentado o mesmo crescimento (ver gráfico 1 ).

Atualmente, $94 \%$ dos estudantes concluem o estudo compulsório de nove anos de duração e $38 \%$ realizam estudos universitários. Além dos estudos acadêmicos, o treinamento no próprio trabalho complementa a formação dos sararimen japoneses, que desenvolvem produtos e processos de forma mais dinâmica que seus concorrentes. Esse dinamismo nos permite afirmar que, enquanto as empresas ocidentais estão preocupadas com o treinamento de Smiths (nome do trabalhador que Taylor usou em seus experimentos), os japoneses preferem educar e treinar Taylors.

O grande dinamismo econômico recente tem tornado obsoletas muitas teorias e modelos, desenvolvidos com base na experiência industrial inglesa ou americana. No esforço de adição ou substituição de velhos modelos e teorias, muitos estudio- sos ocidentais não têm ido além do caráter confuso do desenvolvimento industrial oriental, mais especificamente, do Japão. Por outro lado, análises emocionais e excessivamente ideológicas, por parte de estudiosos japoneses, têm dificultado o avanço do conhecimento sobre a dinâmica do desenvolvimento de suas empresas e das empresas da parte oriental do mundo.

Atividades de negócios ocidentais e, principalmente, orientais, parecem não deixar dúvidas sobre o fato de estratégias, técnicas e formas organizacionais serem influenciadas não somente pelas idéias de alguns empreendedores, mas também pelos aspectos econômicos, sociais e políti$\cos$ de uma nação. Liberdade versus ordem, individualidade versus coletividade, tradição versus inovação, igualdade versus diferença, estagnação versus transformação e aspectos materiais versus aspectos espirituais têm sido os principais pares dicotômicos utilizados na maior parte da literatura econômica e administrativa sobre - Japão do pós-guerra.

Diversas metudologias têm sido utilizadas no estudo do desenvolvimento das empresas e da sociedade japonesas. Freqüentemente, a ênfase dos estudos na área de ciências sociais recai sobre os aspectos culturais, sociais, econômicos e políticos
KODANSHA: HIStory of (Meiji history). v.3 p.193. 


\begin{tabular}{|c|}
\hline O desenvolvimento das \\
partes inconscientes do \\
cérebro através de intensa \\
meditaçáo foi a principal \\
mensagem de zen. \\
Zen procura ensinar os \\
japoneses a estarem mais \\
sintonizados com o lado \\
intuitivo de suas \\
mentes e evitar a confiança \\
exclusiva, e direta, das \\
aproximaçóes lógicas. \\
\hline
\end{tabular}

do Japão. Atividades humanas podem ser consideradas como partes de cada uma dessas denominações. Cada uma delas incorpora as demais, em maior ou menor grau. A vida econômica, política, social ou cultural é necessariamente inter-relacionada.

Aspectos culturais sāo fenômenos mais qualitativos que quantitativos, e parece não existir nenhuma teoria de caráter cultural, universalmente reconhecida, que explique o desenvolvimento econômico de diferentes países ao longo do tempo. Dessa maneira, se as pessoas aceitam os estudos de Weber sobre "a ética protestante e o espírito do capitalismo", de uma forma ou de outra devem aceitar a possivel contribuição da ética confucionista para o desenvolvimento econômico do Japão e de outros países asiáticos.

Alguns aspectos sociológicos relativos a diferentes éticas ocidentais e orientais ou mesmo a princípios que, em última análise, são os principais reguladores e estruturadores da ordem social - podem ser percebidos nos estudos de Gary Hamilton. Em seus estudos, Hamilton faz uma revisão da teoria weberiana da dominação, quando descreve e discute o princípio romano patria potestas e o principio chinês xiao como os dois princípios formadores dessas duas civilizações da Antigüidade.

As diferenças entre esses doís princípios podem ser vistas na relação de obe- diência-dos filhos aos seus pais. Hamilton afirma que "...com patria potestas, uma pessoa obedece a seu pai; com xiao uma pessoa age como filho. Patria potestas define jurisdições dentro das quais uma pessoa pode exercer discrição pessoal e, dessa forma, definir relações de autoridade entre as pessoas. Xiao define papéis e as ações $e$ valores que vão com os papéis; conseqüentemente, define as obrigações pessoais para com um papel. Esses dois conceitos implicam diferentes idéias sobre a nature$z a$ da dominação patriarcal dentro, e especialmente além, da família"s.

O princípio xiao foi transmitido às gerações posteriores através de representativos pensadores em diferentes países da parte oriental do mundo. No Japão, durante o período Tokugawa, o confucionismo recebeu suporte e patrocínio do governo e tornou-se a única ortodoxia do período. No campo religioso, o budismo e o taoísmo continuaram a ser parte das práticas japonesas, com importância declinante. Nos níveis inferiores da sociedade, shinto - uma religião de veneraçāo à natureza e aos ancestrais que tolera contradições e ambigüidades - era predominante.

A tolerância às contradições é um dos fatores cruciais na determinação da realidade social japonesa. Esses fatores foram reproduzidos na vida intelectual japonesa através da repressão política e da influência zen-budista. De zen, de acordo com Durlabhji, "...o povo japonês adquiriu um conjunto de atitudes, entre as quais é predominante a descrença nos processos. lógicos e racionais ${ }^{\prime \prime}{ }^{\text {. }}$ O desenvolvimento das partes inconscientes do cérebro através de intensa meditação foi a principal mensagem de zen. Zen procura ensinar os japoneses a estarem mais sintonizados com o lado intuitivo de suas mentes e evitar a confiança exclusiva, e direta, das aproximaçōes lógicas.

Relacionando o confucionismo com a administração de empresas, Xia Ren Wen argumenta: "O conteúdo do pensamento confucionista cobre uma série de tópicos extremamente ampla, estendendo-se da filosofia à ética, à teoria política, à teoria econômica è à
4. WEBER, Max. A ética protestante e o esplrito do capitalismo. Sāo Paulo: Pioneira, 1987. $233 \mathrm{p}$.

5. HAMILTON, Garry G. Patriarchalism in Imperial China and western Europe: a revision of Weber's sociology of domination. Theory and Society, v. 13, p. 393-426, 1984.

6. DURLABHJI, Subhash, MARKS, Norton E. (eds.) Japanese business: cuitural perspectives. Albany: State University of New York Press, p. 18, 1993. $338 \mathrm{p}$. 
7. WEN, Xia Ren. Confucianism and business management. (Nihon University International Symposium on Economic and Social Development in East Asia: Policies, Management and Population). January 26-29, 1993. Tokyo. Japan. 27 p. p. 2

8. HAYASHI, Shuji. Culture and management in Japan. Tokyo: University of Tokyo Press, p.6. 1988. $194 \mathrm{p}$.

9. Idem, ibidem. educação. Valores confucionistas incluem benevolência, correção, boas maneiras, conhecimento e confiança, mas o pensamento central do confucionismo em seu papel como filosofia é o conceito de benevolência"7.

O confucionismo deposita elevados valores nos ideais humanos, na moralidade, na amizade pessoal e na educação. A perspectiva econômica do confucionismo foi moldada tendo como base a economia natural de uma sociedade feudal. A contribuição do pensamento social e econômico de Confúcio para a admiristração japonesa, como é conhecida nos dias de hoje, é não menos significativa e discutível que a herança das pregações budistas, especialmente as relacionadas à percepção do tempo, às práticas agrícolas tradicionais, aos arranjos de flores, à cerimônia do chá etc.

Com referência às percepções do tempo, Hayashi distingue o "tempo cultural" do "tempo físico" e o classifica em dois padrōes: o linear e o cíclico. Shuji Hayashi argumenta que o tempo linear "...corre do passado para o presente e dai na direçāo do futuro. Ele é linear, como uma linha reta no papel. E ele é escatológico desde que o tempo termina com o julgamento de Deus, ressurreição e imortalidade. Seguidores das rigorosas doutrinas monoteistas como o cristianismo, judaísmo e istamismo - geralmente vivem através

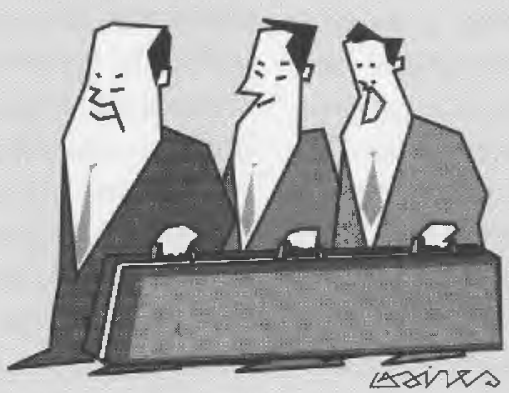

meira Revolução Industrial e, posteriormente, nos Estados Unidos, instituições industriais - como as fábricas, estradas de ferro, estaleiros - foram emergindo durante longo período de tempo. No Japão, entretanto, essas instituições somente apareceram um século mais tarde, após a Restauração Meiji de 1868, quando as atividades privadas de negócios foram liberadas dos controles feudais e o esforço de industrialização foi iniciado.

Para uma maior compreensão desse esforço, e da empresa japonesa, é necessário reconhecer que padrões de conduta, hierarquias sociais, valores e objetivos se produzem e se reproduzem, dentro de estruturas organizacionais diferenciadas de país para país, quando não dentro de um mesmo país. Assim, o desenvolvimento das organizações industriais japonesas (zaibatsu, antes da Segunda Guerra e keiretsu, desde então) são o foco e o fluxo do desenvolvimento econômico japonês. Grupos industriais verticalmente integrados e horizontalmente interligados são estruturas marcantes do processo de desenvolvimento industrial japonês.

No interior dessas estruturas, sistemas administrativos foram desenvolvidos para dar sustentação ao contínuo crescimento das empresas japonesas. A estrutura formal das empresas é um símbodesse padrāo" $0^{\prime \prime}$. Já o padrão cíclico tem um caráter de movimento perpétuo e somente "...seguidores de religiōes politeístas como o hinduismo e o budismo vivem através desse tempo cultural. A metempsicose considera que, quando um ser humano morre, o espírito/alma renasce em outro corpo, humano ou mesmo animal. A transmigração continuamente repete uma eterna volta ao passado"

\section{ESTRUTURAS ADMINISTRATIVAS}

O surgimento das grandes e influentes empresas no Japão é um fenômeno relativamente recente, se olharmos para essa tendência sob uma perspectiva histórica. No Ocidente, na Inglaterra durante a Pri- lo autônomo de relacionamento que pode ser descrito independentemente das orientações de valor de indivíduos e grupos. É um imperativo que deve expressar o que existe nos relacionamentos entre membros de determinada empresa. Dessa forma, a estrutura formal se torna um mecanismo destinado à canalização das energias individuais, dos que decidiram trabalhar nessa ou naquela empresa.

O funcionamento dessas estruturas e da sociedade japonesa se baseia no fato de a autoridade e o poder não atuarem conjuntamente. Por autoridade entende-se a legitimidade ou o reconhecimento social dos direitos de comandar e ser obedecido; por poder, a capacidade de coagir ou de influ- 
enciar os outros a fazerem alguma coisa que, de outra maneira, não fariam. Distintamente de poder, autoridade é amplamente compreendida como inter-relacionada com as noçōes de legitimidade, moral, direito legal e vontade de obediência e obrigação. Poder, por outro lado, pode ser visto como a capacidade de coerção ou de influência.

Parece não existir na vida política e social japonesa característica mais marcante que a separação da autoridade do poder ou vice-versa, do poder da autoridade. Essa separação é melhor representada no mais elevado nível político pela manuitenção e respeito à instituiçăo imperial. É também evidenciada nos negócios diários, onde a maior parte das transações são baseada's em uma hierarquia que permite pouco espaço para o mérito e realizações pessoais e muito espaço para o respeito e lealdade para com os mais velhos. Antigüidade, ou senioridade, é a regra dominante no Japão. Essas características são comuns também no relacionamento entre empresas; nestas, a troca de bens e serviços é mais intensamente baseada em acordos pessoais de confiança do que nas práticas contratuais formais comuns no Ocidente.

No Japão, como a autoridade parece ser mais tradicional - originando-se nos laços pessoais de lealdade a determinada família ou clã - do que legal, a administração do Estado ou de uma empresa é penetrante e difusa, mesmo sendo sua capacidade de compelir e de coerção relativa-

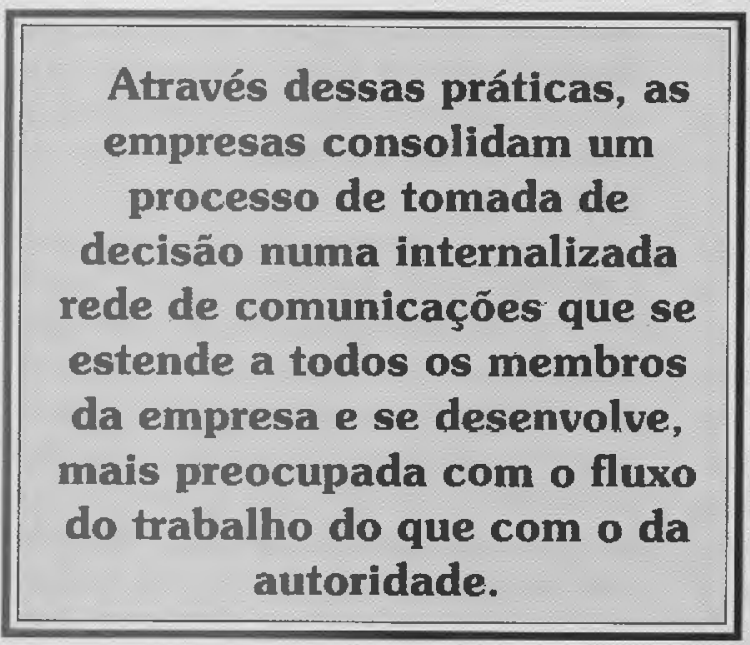

RAE - v. 34 - n. 6 - Nov./Dez. 1994 mente fraca. O resultado disto é a forte dependência de mecanismos extralegais e informais de controle, como meios de manutenção da ordem social, com a concomitante transferência do efetivo controle, acima das regras e.normas que governam qualquer tipo de sociedade, para aqueles que são capazes de manipular os instrumentos informais de imposição.

Fssa manipulação ganha nítidos contornos no interior das empresas japonesas, onde o processo decisório é exercido através da prática do ringi-sho (circular um memorando) e do nemawashi (reuniões informais). Essas práticas estão presentes em todas as atividades de negócios japonesas e caracterizam-se por uma grande centralizaçăo da autoridade pública e / ou privada e uma grande difusão do poder de influência e coerção. Do extensivo uso do sistema ringi e da intensiva prática informal do nemawashi decorrem, a nosso ver, a capacidade japonesa de assegurar a estabilidade de seus padrões de governabilidade e instituições básicas, possibilitando, ao mesmo tempo, um alto grau de mudança social e econômica.

O sistema ringi tem sido praticado com maior ou menor intensidade em todas as grandes empresas privadas. No imediato pós-guerra, as funções da administração eram relativamente não-diferenciadas e a autoridade de cada função não era claramente definida. As unidades empresariais nada mais eram do que escritórios centrais com algumas poucas fábricas diferenciadas. Nestas, as atividades operacionais eram extensivamente controladas através do sistema ringi, que Yoshino afirma ser mais que um simples procedimento: "...ele representa uma filosofia básica da administração profundamente enraizada na tradição japonesa. A palavra ringi consiste de duas partes: rin, significando 'submeter uma proposição para um superior e receber sua aprovação', e gi, sig nificando 'deliberações e decisões'"

Mesmo que as empresas japonesas tenham mudado significativamente em seu processo de expansão e crescimento, o sistema ringi e a prática do nemawashi têm sido extensi-
10. YOSHINO, M. Japan's managerial system: tradition and innovation. Massachussetts: MIT Press, p. 254, 1968. 292 p. 
vamente utilizados pelas mesmas. Através dessas práticas, as empresas consolidam um processo de tomada de decisão numa internalizada rede de comunicaçōes que se estende a todos os membros da empresa e se desenvolve, mais preocupada com o fluxo do trabalho do que com o da autoridade. De acordo com Aoki, “...o empregado permanenté é treinado para desenvolver um amplo número de habilidades e conhecimentos uteis a fim de fazer frente autonomamente aos eventos emergentes nos niveis operacionais designados... A ènfase é para a delegação operacional da solução dos problemas, para aqueles que possuem relevante conhecimento

\section{Figura 1}

A estrutura e o processo de trabalho da empresa japonesa

$$
\text { Mecânico Orgônico "Castelo" }
$$
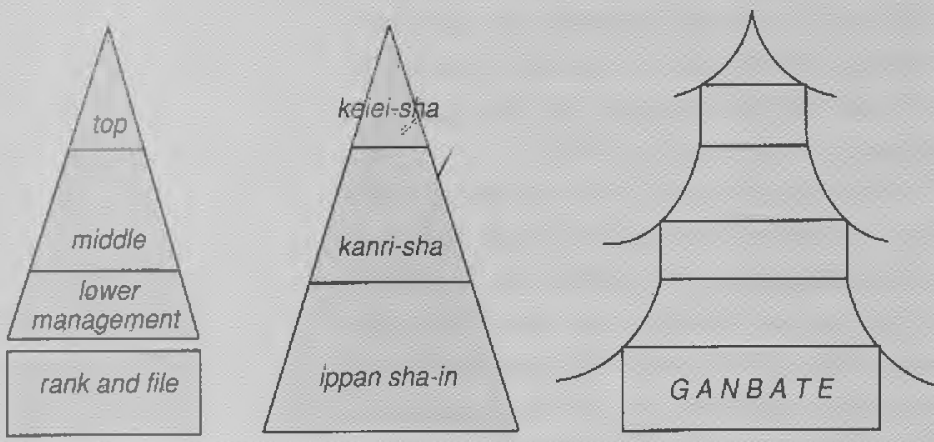

11. AOKI, Masahiko. Information, incentives, and bargaining in the Japanese economy. Cambridge: Cambridge University, 1988. p. 284

12. BALLON, Robert J. Management careers in Japan and the foreign firm. Institute of Comparative Culture. Tokyo: Sophia University, 1990. Business Series № 130.38 p. p. 2 operacional, são mais importantes que as reunióes formais do conselho de administração. Nelas, os problemas relativos às políticas da empresa e de todo o grupo são extensivamente discutidos.

De alguma maneira, o sistema ringi se assemelha à administração por projetos ocidental. É um instrumento útil para assegurar o comprometimento de diferentes departamentos e seções na solução de determinado problema. Devido à circulação entre vários departamentos, comentários e sugestōes são adicionados à proposição inicial do ringi-sho. Até a sua chegada ao ponto final, todos os prós e contras foram considerados, de forma a facilitar a tomada de decisão. Esse processo, além de assegurar que o problema será bem examinado e coordenado antes da tomada de decisão, auxilia na criação de consenso dentro da organização.

A decisão depende dos tomadores de decisões; sua implementação depende do resultado da ação, sempre solicitada no Japão através da imperativa expressão ganbate (esforça-te), de toda a organizaçăo. Nesse aspecto, a estrutura organizacional das empresas japonesas, que cobre as relações entre superiores e subordinados, bem como 0 ambiente econômico japonês, é sensivelmente diferente das empresas ocidentais. Nas empresas japonesas, segundo a descrição de Ballon, "...membros da corporação (sha-in) também incluem os trabalhadores dos níveis de nāo-supervisāo (mas excluem os trabalhadores temporários e de tempo parcial). A estrutura emipresarial é, então, composta por três niveis: um nível executivo, envolvendo os empregados não-supervisores (ippan sha-in); um nível de coordenação, ocupado por gerentes (kanri-sha) e um nivel estratégico, de responsabilidade dos executivos (keiei-sha) ${ }^{\prime \prime 12}$.

Essa estrutura nos permite considerar a possivel fusão dos estereótipos "mecânico" - normalmente atribuído às empresa ocidentais - $\mathrm{e}$ "orgânico" - normalmente atribuído às empresas japonesas -, e sugerir uma outra representação gráfica para melhor retratar a forma de organização no Japão. Essa forma é, na realidade, mecanicamente estruturada pelo sistema ringi-sho e funcional ou organicamente 
praticada através do nemawashi. A estrutura da empresa e seu peculiar processo de trabalho são melhor representados graficamente no estereótipo da estrutura dos castelos japoneses, como visualmente contrastado na figura 1.

A maior parte das estruturas empresariais procura absorver impactos das várias pressões conjunturais do ambiente, internas ou externas. Reestruturaçōes industriais e empresariais são comuns em qualquer parte do mundo industrializado. Na parte oriental do mundo, sistemas "adaptativos-orgânicos" são mais enfatizados do que os "burocráticos-mecânicos", característicos de boa parte das estruturas empresariais do Ocidente.

\begin{tabular}{|c|}
\hline Essas estruturas \\
empresariais japonesas \\
ambiguas coexistem com \\
ambivalentes práticas \\
subjetivas individuais, ao \\
mesmo tempo em que \\
buscam e incentivam uma \\
racional e coletiva \\
objetividade concreta.
\end{tabular}

Sistemas "adaptativos-orgânicos" procuram intensificar não somente a troca de funções, mas também a troca de cargos e responsabilidades na condução de determinadas atividades. Para conduzir de forma integrada e eficaz essas atividades, muito tempo e esforço são necessários. Tempo e esforço são necessários para a reprodução das atividades rotineiras existentes em quaisquer estruturas empresariais, mecânicas ou orgânicas. São necessários também para a sistematizaçằo de possibilidades e/ou transmissão das decisões tomadas em diferentes niveis superiores da empresa.

No caso japonês, nesses diferentes níveís superiores, relações sociais e pessoais particularizadas são mais importantes que as relaçōes profissionais e, estados psico- lógicos, que experimentam ao mesmo tempo, em determinadas situações, sentimentos opostos, são freqüentes e comuns a todos os seus membros. Essas estruturas empresariais japonesas ambíguas coexistem com ambivalentes práticas subjetivas individuais, ao mesmo tempo em que buscam e incentivam uma racional e coletiva objetividade concreta.

Essas estruturas, a exemplo dos castelos, possuem várias janelas, pelas quais muitos "olhos" estão sempre buscando novas e diferentes maneiras de ampliar seus horizontes de atuação. Toda a ênfase parece estar concentrada na ampliação dos aspectos tecnológicos do processo de industrialização, ao mesmo tempo em que peculiaridades culturais são mantidas.

\section{INIMIGOS, ALIADOS OU RIVAIS?}

Ao longo de toda a história, os japoneses, como quaisquer outros povos, foram vistos como inimigos, aliados e rivais. Qualquer forma de relacionamento com o(s) outro(s) passa pela definição de como nos posicionamos frente a determinadas situaçõcs. Dessa forma, não é demais reproduzir, a título de síntese das capabilities chandlerianas presentes nas estruturas japonesas, um amargo poema muito divulgado nos anos 40 nos Estados Unidos. O poema, originalmente publicado na obra From the face is familiar, foi reproduzido pelo professor emérito de Japonês ṇa. Universidade de Colúmbia, Edward Seidenticker, no Journal of the American Academy of Arts and Sciences, no verão de 1990 :

"How courteous is the Japanese; He always says, 'Escuse it, please.' He climbs into his neighbor's garden, And smiles, and says, 'I beg your pardon.' He bows and grins a friendly grin, And calls his hungry family in;

He grins and bows a friendly bow

'Sow sorry, this my garden now'." 。
* Grande parte deste artigo está contida na tese "Empresa japonesa: estruturas, principais as pectos e processo decisório", defendida pelo autor na EAESP/ FGV em outubro de 1994 